\title{
Beryllium Detection in Human Lung Tissue using Electron Probe X-Ray Microanalysis
}

Kelly J. Butnor, M.D., Thomas A. Sporn, M.D., Peter Ingram, Ph.D., Sue Gunasegaram, M.D., John F. Pinto, M.D., Victor L. Roggli, M.D.

Department of Pathology, University of Vermont, Burlington, Vermont (KJB); Department of Pathology, Duke University Medical Center, Durham, North Carolina (TAS, PI, VLR); and Departments of Pathology (SG) and Internal Medical (JFP), St. Rose Dominican Hospital, Henderson, Nevada

Chronic berylliosis is an uncommon disease that is caused by the inhalation of beryllium particles, dust, or fumes. The distinction between chronic berylliosis and sarcoidosis can be difficult both clinically and histologically, as both entities can have similar presentations and exhibit nonnecrotizing granulomatous inflammation of the lungs. The diagnosis of chronic berylliosis relies on a history of exposure to beryllium, roentgenographic evidence of diffuse nodular disease, and demonstration of beryllium hypersensitivity by ancillary studies, such as lymphocyte proliferation testing. Additional support may be gained by the demonstration of beryllium in lung tissue. Unlike other exogenous particulates, such as asbestos, detection of beryllium in human lung tissue is problematic. The low atomic number of beryllium usually makes it unsuitable for conventional microprobe analysis. We describe a case of chronic berylliosis in which beryllium was detected in lung tissue using atmospheric thinwindow energy-dispersive $\mathrm{X}$-ray analysis (ATW EDXA). A woman with a history of occupational exposure to beryllium at a nuclear weapons testing facility presented with progressive cough and dyspnea and a nodular pattern on chest roentgenograph. Open lung biopsy showed nonnecrotizing granulomatous inflammation that was histologically indistinguishable from sarcoidosis. Scanning electron microscopy and ATW EDXA demonstrated particulates containing beryllium within the granulomas. This application of EDXA offers significant advantages over existing methods of beryllium detection in that it is nondestructive, more widely

Copyright () 2003 by The United States and Canadian Academy of Pathology, Inc.

VOL. 16, NO. 11, P. 1171, 2003 Printed in the U.S.A.

Date of acceptance: July 18, 2003.

Address reprint requests to: Kelly J. Butnor, M.D., Fletcher Allen Health Care, MCHV Campus, Smith 246B, 111 Colchester Avenue, Burlington, VT 05401; fax: 802-847-4155; e-mail: kelly.butnor@vtmednet.org.

DOI: 10.1097/01.MP.0000094090.90571.ED available, and can be performed using routine paraffin sections.

KEY WORDS: Atmospheric thin-window energy dispersive X-ray analysis, Beryllium, Chronic berylliosis, Sarcoidosis, Scanning electron microscopy.

Mod Pathol 2003;16(11):1171-1177

Beryllium is a naturally occurring metal that is found in a number of minerals, such as beryl ore, with unique physicochemical properties that make it suitable for a variety of industrial and technologic applications. Although it is the second lightest known metal, beryllium is more rigid than steel, has an unusually high melting point, and is an excellent conductor of heat and electricity (1). Commonly alloyed with other metals, such as copper and aluminum, beryllium is an important component in the manufacture of aerospace equipment, computers, electronics, industrial ceramics, nuclear reactors and weapons, dental prostheses, and even some golf clubs.

Despite its desirable properties, beryllium and beryllium-containing compounds are toxic to humans. The adverse pulmonary effects of beryllium became evident during the first half of the 20th century, with the development of acute chemical pneumonitis in beryllium extraction workers (2). Subsequently, disease similar to sarcoidosis was described in workers who were exposed to beryllium phosphors used to produce fluorescent lamps (3). Improved industrial practices and limitations imposed on workplace exposure have markedly reduced the incidence of beryllium-induced lung disease, in particular, acute beryllium pneumonitis (4). However, an acceptable substitute for beryllium has not been identified for many applications. Consequently, an estimated 807,000 individuals are presently at risk of developing beryllium disease (5).

Unlike acute beryllium disease, which manifests as a chemical pneumonitis, chronic berylliosis, or chronic beryllium disease, is a systemic disorder 
believed to result from delayed-type hypersensitivity to beryllium. It is characterized by nonnecrotizing granulomatous inflammation in the lungs and several other organs. Remarkably similar clinical and histopathologic features can be seen in sarcoidosis. Although a history of occupational exposure is usually apparent, detection of elevated levels of beryllium in lung tissue may be helpful in establishing the diagnosis.

Several techniques are employed for detection of beryllium in lung tissue, including electron energy loss spectroscopy (6), laser microprobe mass analysis (7), and secondary ion mass spectrometry (8). Although highly sensitive, these modalities are relatively expensive and not widely available in the clinical setting. At least $1 \mathrm{~g}$ of lung tissue is required by some of these techniques, most of which destroy the tissue undergoing analysis (9).

Conventional energy-dispersive X-ray analysis (EDXA) is a nondestructive technique that has been in use for $>30$ years. In such instruments, the cooled lithium-drifted silicon detector $[\mathrm{Si}(\mathrm{Li})]$ is protected in a vacuum by a thin beryllium window. Elements of atomic number $\geq$ fluorine $(Z=9)$ can be detected by conventional EDXA, but low-energy $\mathrm{X}$-rays are absorbed by the beryllium window. Newer polymeric atmospheric thin-window (ATW) EDXA detectors are theoretically capable of detecting lower atomic number elements such as beryllium $(Z=4)(10)$. To our knowledge, detection of beryllium in human lung tissue using EDXA has not been reported.

We report a case of a woman with a history of beryllium exposure who developed cough and progressive dyspnea, accompanied by bilateral hilar adenopathy and nodular parenchymal disease. Examination of lung tissue by scanning electron microscopy (SEM) and ATW EDXA demonstrated particles of beryllium within granulomas.

\section{CASE REPORT}

\section{Clinical History}

The patient was a 40 year-old Caucasian female nonsmoker. Her past medical history was significant for allergic rhinitis and depression, for which she took Zyrtec and Effexor. She was exposed to beryllium through her employment as a geologist at a nuclear weapons testing facility.

The patient was in her usual state of good health until 2 years before presentation, at which time she developed a persistent cough and dyspnea on exertion, associated with bilateral hilar adenopathy and diffuse nodular pulmonary parenchymal disease on chest radiographs. Physical examination disclosed normal chest auscultation. There were no ocular or mucosal membrane abnormalities. Pulse oximetry on room air at rest showed an arterial oxygen saturation of $96 \%$. Pulmonary function tests demonstrated mild restrictive lung disease and a very mild reduction in diffusing capacity. Ancillary studies included serologic tests for coccidioidomycosis, which were negative. The clinical impression was sarcoidosis. Open biopsy of the right lung was performed. Following histopathologic examination, the patient was counseled to avoid further exposure to beryllium in the workplace. Lymphocyte proliferation testing for beryllium was also performed, which was positive. In the 14 months subsequent to diagnosis, the patient has experienced some symptomatic relief with Flovent, and her pulmonary function tests have remained stable.

\section{Pathologic Findings}

Grossly, the lung parenchyma was gray with a rubbery, nodular consistency. Histologic sections showed clusters of well-formed nonnecrotizing granulomas with multinucleated giant cells, mainly along bronchovascular bundles (Fig. 1). The surrounding parenchyma showed mild chronic interstitial inflammation, but fibrosis and honeycombing were absent. Examination with polarizing light microscopy demonstrated minute round birefringent particles in the granulomas, which were predominantly within the cytoplasm of multinucleated giant cells.

A beryllium-free carbon disc was examined in a JEOL-JSM 6400 scanning electron microscope (JEOL USA, Inc., Peabody, MA) equipped with a Robinson backscatter electron image detector (ETP-USA/Electron Detectors, Inc., Rocklin, CA), a Gresham Sirius $30 \mathrm{~mm}^{2}$ X-ray detector (Gresham Scientific Instruments Ltd., Buckinghamshire, England), and a 4pi Analysis microanalyzer and pulse processor (4pi Analysis, Inc., Durham, NC). An accelerating voltage of $5 \mathrm{keV}$ was used. The disc was probed, and the low energy threshold discriminator was set to allow acquisition of X-ray pulses of approximately $0.04 \mathrm{keV}$ and greater, while excluding pulses from the zero energy reference peak. This ensured that no spurious peaks would be visualized in the region corresponding to beryllium $(\sim 0.11$ $\mathrm{keV}$ ). A pure beryllium grid was then mounted on an aluminum disc and examined in a similar manner. With negative backscattered electron imaging (BEI), the beryllium grid appeared bright on a darker aluminum background (Fig. 2). EDXA yielded peaks for beryllium. A $128 \times 128$ pixel (beam current, 10-8 amps, 6 sec/pixel dwell time) elemental X-ray image set showed distributions consistent with the morphology of the grid and its specimen support (Fig. 2) (11). Beryllium and the aluminum support were clearly visualized, as was carbon contamination on the grid. The peak-free 


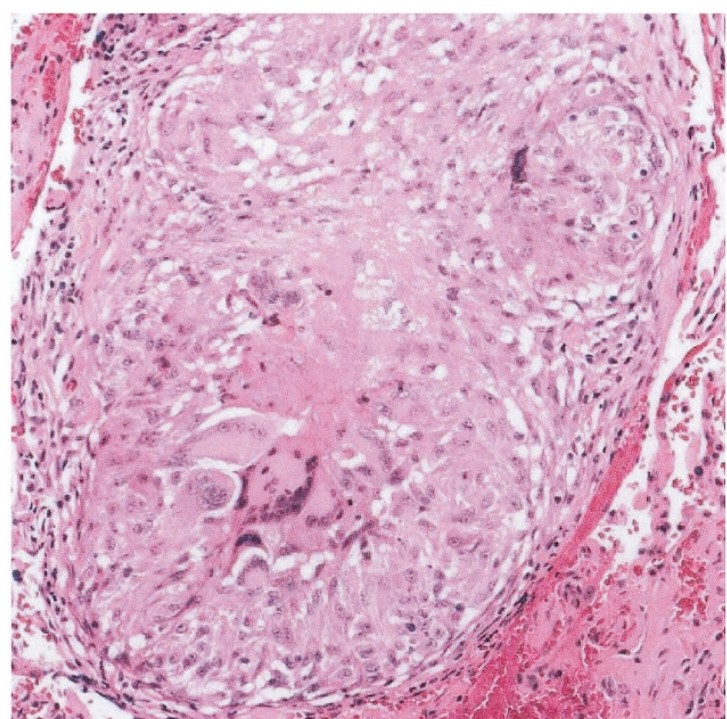

FIGURE 1. Lung tissue with nonnecrotizing granulomas (H\&E, original magnification, $200 \times$ ).

background showed no localization, and the sulfur was minimal (probably contamination).

Elemental maps were acquired with the spectrum imaging software "ImagNSpect" (DAKX, LLC, Pittsboro, NC) (12). Acquisition could be programmed such that more dwell time per pixel occurred in regions suspected to contain beryllium. Spectra were obtained from the data set post facto and image processing was performed on individual maps.

A 5 micron thick section of paraffin-embedded lung tissue was mounted on a carbon stub, depar- affinized by thorough washing with xylene, lightly rotary coated with carbon, and examined by secondary electron imaging (SEI), BEI, and EDXA. Areas with giant cells were readily identified by SEI (Figs. 3, 4A). With negative BEI, a few bright, round to irregular, 0.5 - to $3-\mu \mathrm{m}$ particles were seen in the cytoplasm of giant cells (Fig. 4B). Such particles were not apparent in surrounding nongranulomatous tissue. EDXA of the particles yielded discrete peaks for beryllium (Fig. 5A). Spectra from lung tissue devoid of particles yielded either no or trace peaks for beryllium (Fig. 5B). The only other elements identified were carbon and in some areas, oxygen. Elemental maps were performed using the same procedure described above for the beryllium grid and aluminum stub. To display the beryllium effectively, it was useful to normalize the beryllium to the carbon map. This procedure suggested the presence of beryllium in the region of a particle identified by BEI imaging (Fig. 6). As a control, pulmonary tissue from a case of nonnecrotizing granulomatous inflammation with clinical features consistent with sarcoidosis and a negative beryllium exposure history was subjected to similar analysis. BEI-positive particles were not identified. EDXA of the granulomas did not demonstrate any beryllium peaks.

\section{DISCUSSION}

The U.S. Beryllium Case Registry has established criteria for diagnosing chronic berylliosis (13). A history of beryllium exposure is essential to the
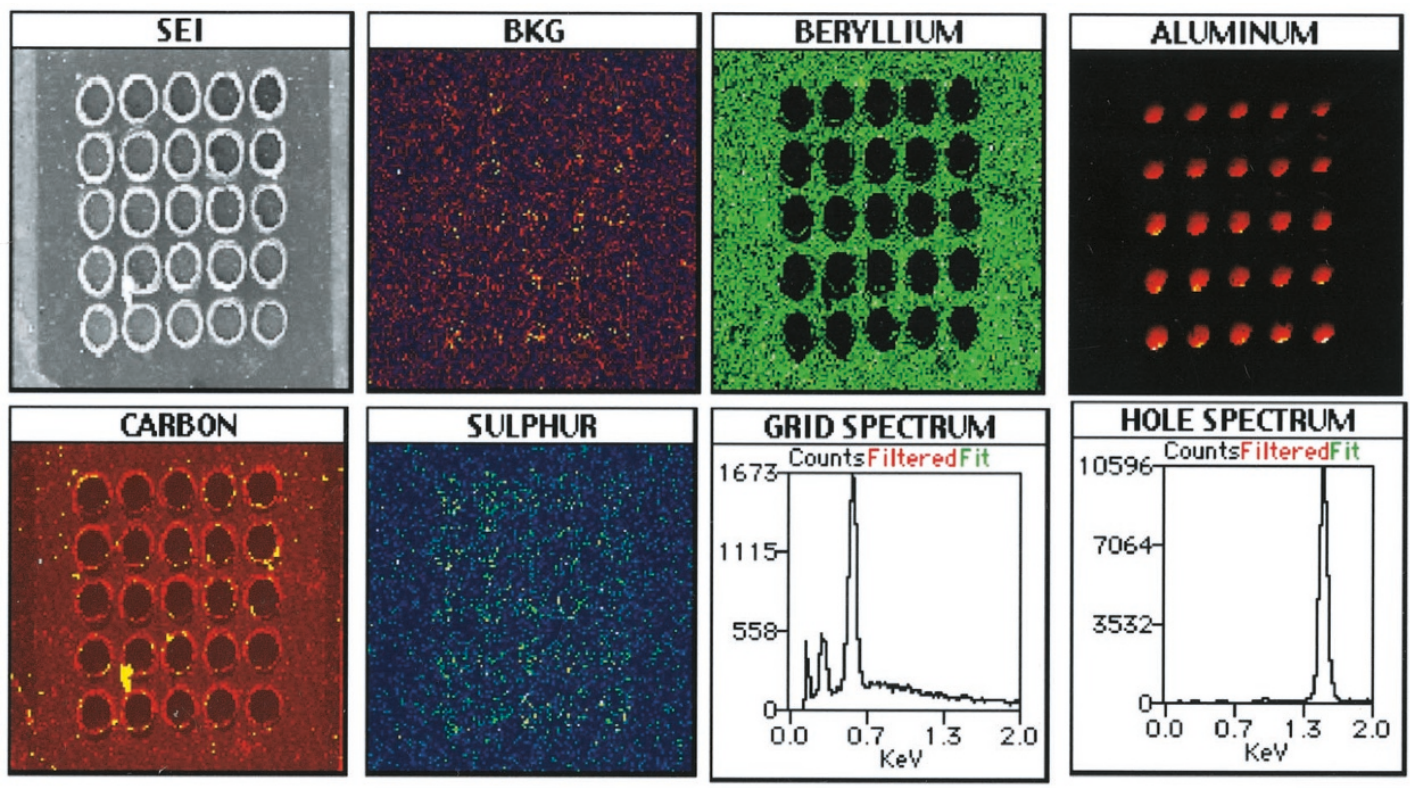

FIGURE 2. Beryllium grid mounted on an aluminum stub. First panel, top row: secondary electron image. Second panel: background (bremsstrahlung) X-ray spectrum. Third panel: X-ray map for beryllium. Fourth panel: X-ray map for aluminum. First panel, bottom row: X-ray map for carbon, showing some contamination with organics. Second panel: X-ray map for sulfur. Third panel: EDXA spectrum from grid, showing peaks for beryllium, carbon, and oxygen (left to right). Fourth panel: EDXA spectrum from hole in grid, showing peak for aluminum. 


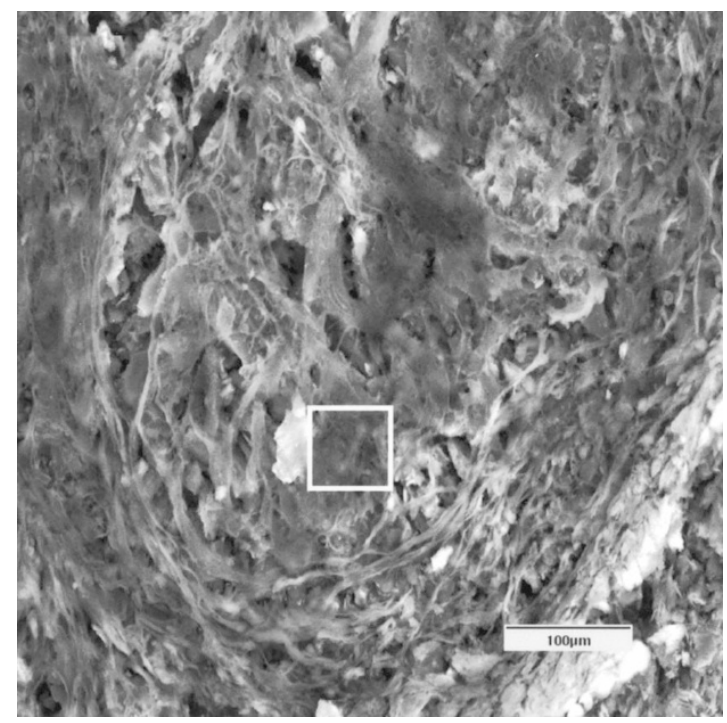

FIGURE 3. Scanning electron image of granuloma with multinucleate giant cells. Boxed area detailed in Figure 4A (original magnification, $450 \times)$.
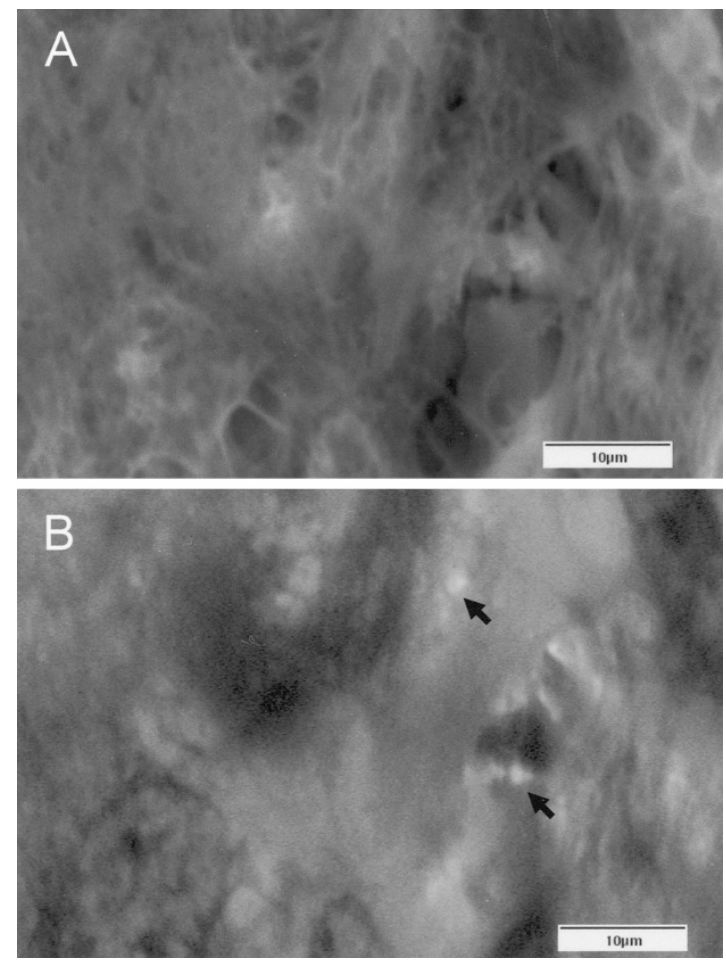

FIGURE 4. A, high-power secondary electron image from boxed area in Figure 3. B, negative backscatter electron image of several backscatter-positive particles in the cytoplasm of a multinucleate giant cell (arrowheads; original magnification, $4500 \times$ ).

diagnosis. Although exposure may be obvious, as in cases arising in beryllium extraction workers, chronic berylliosis has been documented in individuals without direct exposure. Reported examples include household contacts of beryllium workers, secretaries, and janitors at factories where beryllium is used, and residents of neighborhoods near
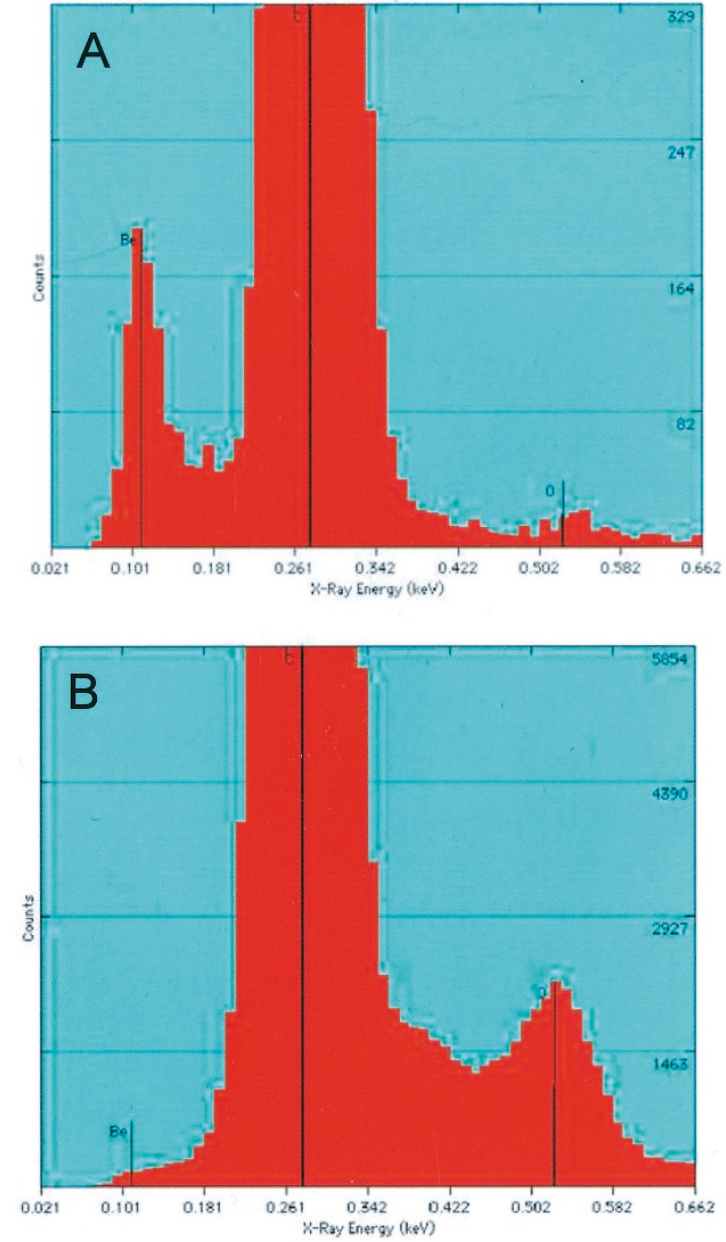

FIGURE 5. A, energy dispersive X-ray analysis spectrum of an intracytoplasmic backscatter-positive particle shows discrete peaks for beryllium (Be). B, spectrum from area away from particles with a prominent peak for oxygen $(\mathrm{O})$. Only background signal is seen in the Be region $(\sim 0.1 \mathrm{keV})$.

such factories (14-17). Chronic berylliosis may also arise in beryllium workers long after exposure has ceased, with a reported latency period of $\leq 40$ years (18).

With respect to the present case, chronic berylliosis has been well documented in nuclear weapons workers $(14,19,20)$. As with other industries in which beryllium is used, the risk of developing disease increases with the level of exposure, with the highest rates reported in nuclear weapons machinists (14). Chronic berylliosis has also been documented in employees with unknown incidental or passive exposure, such as clerical workers and security guards at nuclear weapons facilities, albeit at a much lower rate (14).

Two other criteria for the diagnosis of chronic berylliosis include appropriate clinical and histologic findings. Such findings, which were apparent in the present case, do not readily allow distinction from sarcoidosis (9). Histologically, the appearance of chronic berylliosis is often indistinguishable 

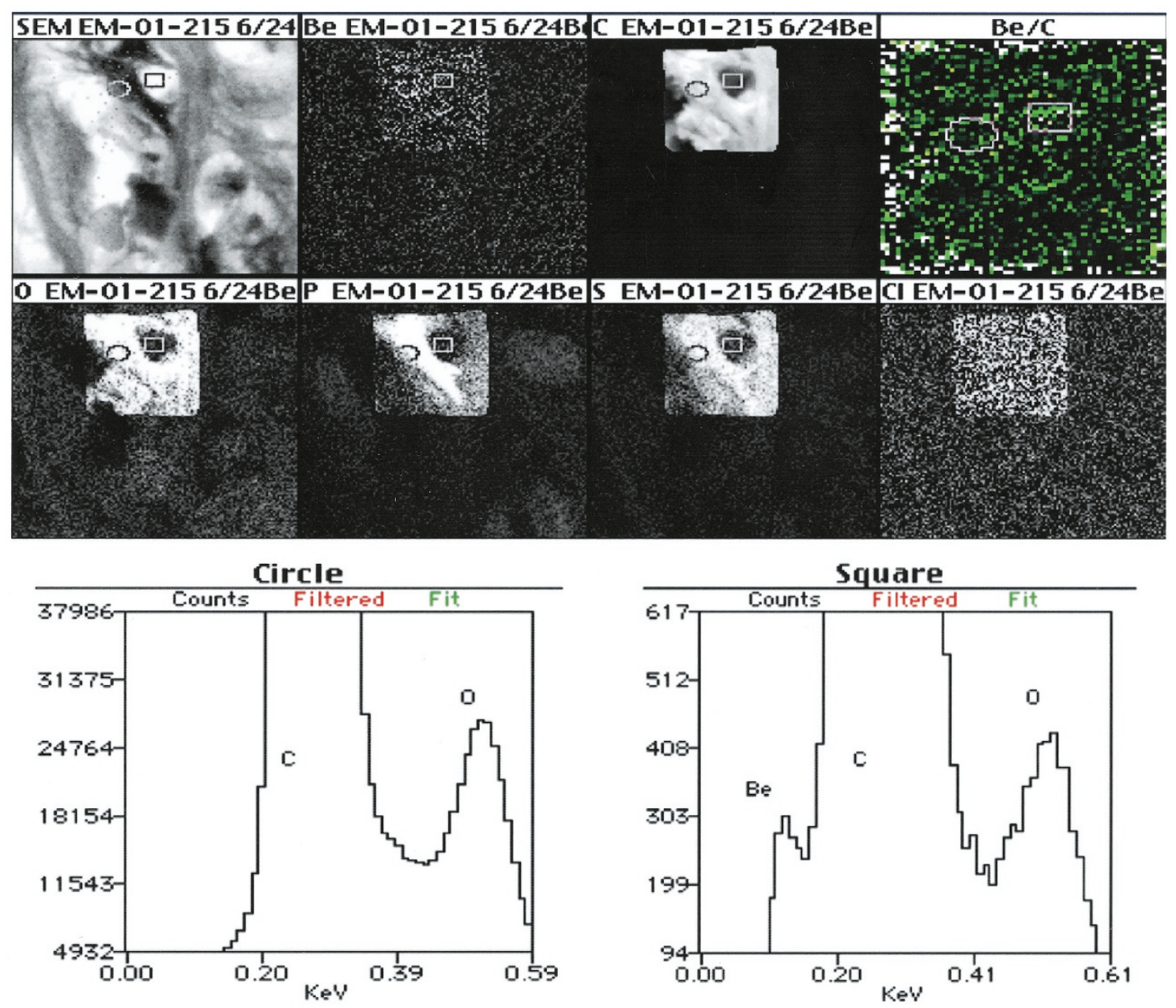

FIGURE 6. Highly magnified image and X-ray maps of beryllium particle within a granuloma. First panel, top row: negative backscattered electron image, showing bright particle on gray background. Square denotes particle. Second panel: beryllium X-ray map showing strong signal in region of particle. Third panel: carbon X-ray map. In the region of the beryllium particle, no signal is present. Fourth panel: beryllium and carbon X-ray maps expressed as a ratio. There is a suggestion of peak intensity in the region of the beryllium particle. First three panels, second row: X-ray maps for oxygen, phosphorus, and sulfur, respectively. In the region of the beryllium particle, no signal is present. Fourth panel: X-ray map for chlorine. First panel, bottom row: EDXA spectrum from reference point (circle), showing carbon and oxygen but no beryllium. Second panel: EDXA spectrum from particle (square), showing carbon, oxygen, and beryllium. The beam dwell time for the field encompassing the circle and small box is 10 seconds per pixel, whereas dwell time for the remainder of image is 1 second per pixel.

from sarcoidosis. Well-formed, compact, nonnecrotizing "sarcoid-like" granulomas composed of epithelioid histiocytes are typically distributed along bronchovascular bundles and lymphatics (21). Schaumann bodies may be present within the giant cells of granulomas and are sometimes prominent. The interstitium in chronic berylliosis exhibits a variable degree of inflammation, ranging from mild to prominent $(22,23)$. Interstitial fibrosis often accompanies the infiltrate, which may progress to microscopic honeycombing. Histologically similar granulomatous disease has been associated with a variety of metals other than beryllium, including aluminum, barium, cobalt, copper, gold, rare earths (lanthanides), titanium, and zirconium, again emphasizing the importance of exposure history (24).

Because the clinical, radiographic, and histopathologic findings in berylliosis are nonspecific, a fourth criterion, which must be met to establish a diagnosis of chronic berylliosis, is demonstrating a beryllium-specific immune response (14). Chronic berylliosis is postulated to be a Type IV hypersensitivity disorder, in which beryllium binds as a hapten to tissue proteins and is recognized as foreign by the immune system, thereby inducing a cellular immune response (25). Host susceptibility appears to be an important factor in the pathogenesis of chronic berylliosis. Of the approximately 800,000 exposed individuals, only about $2 \%$ develop disease (26). Interestingly, the human leukocyte antigen DPB1 is particularly prevalent among individuals with chronic berylliosis (27).

Several methods for demonstrating a berylliumspecific immune response have been devised. Currently, beryllium lymphocyte proliferation testing is preferred. This technique, which can be performed 
on lymphocytes from blood or bronchoalveolar lavage, compares the proliferation response of lymphocytes incubated with a beryllium-containing compound from a patient suspected to be sensitized to beryllium to that of a nonsensitized individual (26). A positive lymphocyte proliferation test was demonstrated in the present case, thereby fulfilling the four criteria for a diagnosis of chronic berylliosis. A major criticism of using beryllium hypersensitivity as a criterion for diagnosing chronic berylliosis is that hypersensitivity does not necessarily equate with clinical disease.

An alternative approach to the diagnosis of chronic berylliosis is the demonstration of beryllium in lung tissue, lymph nodes, or urine (13). Because of its low atomic number, beryllium is not detected by conventional EDXA. However, atmospheric thin-window technology has expanded the range of detectable elements. Unlike currently employed methods, which include spectrographic and fluorometric analysis, EDXA is available at most academic medical centers. Adding atmospheric thin-window detection capabilities to X-ray analyzers is relatively straightforward, as is learning how to perform ATW analysis.

The ability to use routine sections prepared from paraffin blocks for beryllium detection is perhaps the most significant advantage of ATW EDXA. This is because the diagnosis of chronic berylliosis is often considered in retrospect, after lung biopsy shows nonnecrotizing granulomas and a detailed occupational history is obtained. By this time, the opportunity to retain fresh or even formalin-fixed tissue often has passed.

Over time, beryllium is largely removed from tissue, excreted mainly in the urine (28). Patients with massive exposure who develop acute berylliosis have high levels of beryllium in their lungs (29). In cases of chronic berylliosis, beryllium levels vary widely, but are usually significantly less than those observed in acute berylliosis $(29,30)$. Background levels of beryllium are present in the environment, such that tissue from individuals with no known exposure may exhibit low levels of beryllium (30, 31). It is important to note that analyzed cases of sarcoidosis, the main entity to be distinguished from chronic berylliosis, have not demonstrated levels of beryllium above background (30). It is necessary to study additional cases of confirmed berylliosis and sarcoidosis to establish the sensitivity and specificity of ATW EDXA for the detection of beryllium in tissues. If ATW EDXA proves to be a good discriminator between berylliosis and sarcoidosis, this technique could serve as a powerful adjunct to or supplant berylliosis lymphocyte proliferation testing.

The combination of BEI with ATW EDXA is a powerful approach, because the former permits the detection of suspected particles of beryllium within areas of granulomatous inflammation. Most inorganic particulates in the lung are heavier than carbon and therefore appear as dark areas on a lighter background with negative BEI. Because beryllium is lighter than carbon, it appears as pinpoint areas of brightness on a darker background (Fig. 4B). Conventional BEI detectors can readily discriminate between carbon $(Z=6)$ and beryllium $(Z=4$; Fig. 2$)$. Once a potential beryllium particle has been identified with BEI, ATW EDXA can then confirm its composition as beryllium. It is essential when performing ATW EDXA to set the low-energy threshold discriminator appropriately to insure that spurious low energy peaks potentially confused with beryllium are not displayed.

Obtaining a thorough occupational history is paramount to the accurate diagnosis of nonnecrotizing granulomatous pulmonary disease. Although sarcoidosis is the most likely cause, chronic berylliosis should always be included in the differential diagnosis. The diagnosis of chronic berylliosis can be aided by demonstrating beryllium in tissue. Until the present time, this required spectrographic or fluorometric methods. We have demonstrated that atmospheric thin-window energy dispersive X-ray analysis is technically feasible tool for detecting beryllium in human lung tissue, which has the advantage of using routine paraffin sections. Further investigation is necessary to determine the overall sensitivity and specificity of this exciting new technique before it can be implemented in the diagnostic evaluation of suspected chronic beryllium disease.

Acknowledgments: The authors thank Eve Whalin and Walter Fennel for assistance in preparation of specimens for mineral analysis and thank Dr. Arthur del Rosario for referral of the case.

\section{REFERENCES}

1. Lang L. Beryllium. A chronic problem. Environ Health Perspect 1994;102:526-31.

2. Van Ordstrand HS, Hughes R, Carmody MG. Chemical pneumonia in workers extracting beryllium oxide: report of 3 cases. Cleve Clin Q 1943;10:10.

3. Hardy JL, Tabershaw IR. Delayed chemical pneumonitis occurring in workers exposed to beryllium compound. J Ind Hyg Toxicol 1946;28:197.

4. Eisenbud M. Commentary and update: chemical pneumonia in workers extracting beryllium oxide. Cleve Clin Q 1984;51: 441-7.

5. Sanderson WT. The US population at risk to occupational respiratory disease. In: Merchant JA, editor. Occupational respiratory disease. Publication no. 86-102. Department of Health and Human Services (NIOSH): 1986; p. 739-59.

6. Dinsdale D, Bourdillon AJ. The ultrastructural localization of beryllium in biological samples by electron energy-loss spectrometry. Exp Mol Pathol 1982;36:396-402. 
7. Williams WJ, Wallach ER. Laser microprobe mass spectrometry (LAMMS) analysis of beryllium, sarcoidosis and other granulomatous diseases. Sarcoidosis 1989;6:111-7.

8. Levi-Setti R, Berry JP, Chabala JM, Galle P. Selective intracellular beryllium localization in rat tissue by mass-resolved ion microprobe imaging. Biol Cell 1988;63:77-82.

9. Parkes WR. Occupational lung disorders. 2nd ed. Boston: Butterworths; 1982. p. 333-58. Richeldi L, Sorrentino R, Saltini C. HLA-DPB1 glutamate 69: a genetic marker of beryllium disease. Science 1993;262:242-4.

10. McDonald JW, Roggli VL, Churg A, Shelburne JD. Microprobe analysis in pulmonary pathology. In: Ingram $\mathrm{P}$, Shelburne J, Roggli V, LeFurgey A, editors. Biomedical applications of microprobe analysis. San Diego, CA: Academic Press; 1999. p. 201-56.

11. Ingram P, Shelburne JD, LeFurgey A. Principles and instrumentation. In: Ingram P, Shelburne J, Roggli V, LeFurgey A, editors. Biomedical applications of microprobe analysis. San Diego, CA: Academic Press; 1999. p. 1-57.

12. Ingram $P$, Kopf DA, LeFurgey A. Quantitative imaging in biology. Scanning 1998;20:190-2.

13. Sprince NL, Kazemi H. Beryllium disease. In: Environmental and occupational medicine. Rom WN, editor. Boston: Little, Brown; 1984. p. 481-90.

14. Kreiss K, Mroz MM, Zhen B, Martyny JW, Newman LS. Epidemiology of beryllium sensitization and disease in nuclear workers. Am Rev Respir Dis 1993;148:985-91.

15. Kreiss K, Wasserman S, Mroz MM, Newman LS. Beryllium disease screening in the ceramics industry. Blood lymphocyte test performance and exposure-disease relations. J Occup Med 1993;35:267-74.

16. Newman LS, Kreiss K. Nonoccupational beryllium disease masquerading as sarcoidosis: identification of blood lymphocyte proliferative response to beryllium. Am Rev Respir Dis 1992;145:1212-4.

17. Eisenbud M, Wanta RC, Dustan C, Steadman LT, Harris WB, Wolf BS. Nonoccupational berylliosis. J Ind Hyg Toxicol 1949;31:282-94.
18. Eisenbud M, Lisson J. Epidemiological aspects of berylliuminduced nonmalignant lung disease: a 30-year update. J Occup Med 1983;25:196-202.

19. Viet SM, Torma-Krajewski J, Rogers J. Chronic beryllium disease and beryllium sensitization at Rocky Flats: a casecontrol study. Aihaj 2000;61:244-54.

20. Stange AW, Hilmas DE, Furman FJ, Gatliffe TR. Beryllium sensitization and chronic beryllium disease at a former nuclear weapons facility. Appl Occup Environ Hyg 2001;16:405-17.

21. Jones Williams W. A histological study of the lungs in 52 cases of chronic beryllium disease. Br J Ind Med 1958;15:84-91.

22. Churg A, Colby TV. Disease caused by metals and related compounds. In: Churg A, Green FHY, editors. Pathology of occupational lung disease. 2nd ed. Baltimore: Williams \& Wilkins; 1998. p. 103-20.

23. Gibbs AR. Occupational lung disease. In: Hasleton PS, editor. Spencer's pathology of the lung. 5th ed. New York: McGrawHill; 1996. p. 485-7.

24. Newman LS. Metals that cause sarcoidosis. Semin Respir Infect 1998;13:212-20.

25. Daniele RP. Cell-mediated immunity in pulmonary disease. Hum Pathol 1986;17:154-60.

26. Newman LS. Immunology, genetics, and epidemiology of beryllium disease. Chest 1996;109:40s-4s.

27. Richeldi L, Sorrentino R, Saltini C. HLA-DPB1 glutamate 69: a genetic marker of beryllium disease. Science 1993;262: 242-4.

28. Fraser RS, Pare JAP, Fraser RG, Pare PD. Pleuropulmonary disease caused by inhalation of inorganic dust (pneumoconiosis). In: Synopsis of diseases of the chest. 2nd ed. Philadelphia: Saunders; 1994. p. 732.

29. Dutra FR. The pneumonitis and granulomatosis peculiar to beryllium workers. Am J Pathol 1948;24:1137-52.

30. Sprince NL, Kazemi H, Hardy HL. Current problem of differentiating between beryllium disease and sarcoidosis. Ann N Y Acad Sci 1976;654-64:1975.

31. Cholak J. The analysis of traces of beryllium. Arch Ind Health 1959;19:205-10 